\title{
QUEM CONTA UM CONTO, AUMENTA UM PONTO, QUEM RESENHA, AUMENTA VÁRIOS
}

MARTELETO, Regina Maria; TOMAÉL, Maria Inês. A metodologia de análise de redes sociais. In.: VALENTIN, Marta Lígia Pomim (Org.). Métodos qualitativos de pesquisa em Ciência da Informação. São Paulo: Polis, 2005. p.81-100.

A solicitação para esta resenha se origina de convite de professores da Universidade Estadual de Londrina (UEL), por quem tenho apreço e particular carinho. Portanto, irrecusável e honroso. A resenha se caracteriza por resumir o conteúdo de um texto, inserindo-Ihe comentários e avaliações. Justifico, assim, o título. Sugeremme as professoras da UEL o capítulo: $A$ metodologia de análise de redes sociais, em que a Doutora Regina Marteleto e a doutoranda Maria Inês Tomaél, estudiosas das redes sociais e das estruturas de funcionamento, disponibilizam sua experiência e conhecimento em metodologia de análise do objeto de suas pesquisas. A primeira, professora-amiga, da UFRJ/IBICT, e amiga pela vida afora; e a segunda, com quem estabeleci ligações (tie, já usando os ter- mos do texto em resenha) eletrônicas, na realização de obra coletiva.

A Análise de Redes Sociais (ARS) surge especialmente da Antropologia Cultural e da Sociologia, com aplicações em disciplinas que focalizem as interações entre os indivíduos, como forma de compreender a relação estrutural e relacional da sociedade. Aprecio a atividade da resenha, exatamente porque, objetivo divulgá-la e, por via de conseqüência, o livro Métodos qualitativos de pesquisa em Ciência da Informação e uso em causa própria, para identificar o que melhor se aplica às relações que desfrutamos nessa rede. Em suma, junto o agradável ao útil.

Por isso, traduz-se em importância entender o funcionamento das instituições ou dos campos, enquanto estruturas que visam determinar ações e representações 
dos sujeitos sociais e as decorrentes relações, ou seja, o(s) modo(s) como os sujeitos, vivendo coletivamente, reproduzem, enfrentam ou modificam as estruturas sociais, campos de estudo das Ciências Sociais. Segundo as autoras, os dois campos se utilizam das correntes objetiva e subjetiva, que privilegiam as macroestruturas ou as micro-situações e os métodos quantitativos e qualitativos de análise.

A referência aos métodos quantitativos e qualitativos me faz relembrar quão inócuo é privilegiar um em detrimento do outro. "Comedores de números" e "contadores de histórias" são termos ofensivos, utilizados por uns contra os outros. Aliás, quando a Escola de Chicago surgiu, os "estranhos no ninho" eram os estudos de caso, as histórias de vida e as autobiografias. A ciência natural só admitia a representação da realidade por meio de dados estatísticos, contagiando as demais áreas científicas.

Mas Regina e Maria Inês apresentam as possibilidades oferecidas por uma abordagem e por outra, no capítulo, $A$ metodologia de análise de redes sociais, e defendem que a combinação dos dois métodos para coleta e interpretação dos dados "acrescenta valor interpretativo aos dados empíricos". E "após a sistematização dos dados, as abordagens qualitativas e quantitativas deixam de ser elementos singulares e começam a influenciar a análise no seu todo, permitindo qualificar as posições e relações de interdependência entre os atores e ressaltando os papéis por eles desempenhados e as aberturas das relações para o ambiente externo das redes e seu contexto de ação".

De outra parte, elas focalizam os conceitos operacionais para a análise - a informação, a comunicação e o conhecimento; as unidades de análise: as relações (relations), também chamadas de fios ( $s$ trands), caracterizando-se pelo conteúdo, pela direção e intensidade; e as ligações (tie), pelos vínculos que conectam um par de atores em uma ou mais relações. Já as formas de análise indicadas são a rede egocêntrica e a rede total ou completa, representadas, no texto, por ilustrações que correspondem a um e outro modelo. O capítulo em resenha inclui as propriedades e divisões da rede, a análise posicional e a centralidade. Esta última para identificar os indivíduos-chave na rede.

Sobre a coleta de dados, as autoras afirmam que, raramente, determina-se uma amostragem e que as populações "podem ser desde símbolos de um texto, sons de pronúncia, até nações do mundo". Porém, as mais comuns situam-se em todos os membros de uma corporação ou em um grupo delimitado pela territorialidade. Como instrumentos, são usados questionários, entrevistas, diários, observações e monitoramento, por meio do computador. 
Dentre as técnicas mais usadas, está a bola de neve, com a indicação sucessiva dos pares e ainda a que utiliza membros de uma comunidade para selecionar os pares em uma lista constante de todos os nomes.

Os procedimentos de análise, configuração e diagramação para identificar as medidas das redes contam, na atualidade, com softwares tais como: ucinet, netdraw, egonet, inflow, negopy, netminer, pajek e frackplot, todos com respectivos endereços eletrônicos. As pesquisadoras ressaltam que os softwares analisam quantitativamente a configuração da rede, e a leitura qualitativa agrega novos enfoques, comparações e interpretações às relações dentro do contexto social.

Todos os elementos constitutivos da metodologia são abordados e embora, pelo título, o livro se destine aos cientistas da informação, eles não se constituem o único público a se beneficiar com as informações disponibilizadas. Acredito que a descrição do capítulo demonstre a riqueza de detaIhes e a clareza com que cada metodologia foi tratada e, dessa forma, estimule e amplie a utilização da obra por outros públicos interessados na pesquisa científica. É a que se propõe a resenha! Por último, informações do currículo das autoras deste capítulo, e dos autores dos demais podem ser encontradas ao final.
Joana Coeli Ribeiro Garcia Doutora em Ciência da Informação, UFRJ/IBICT Professora da Universidade Federal da

Paraíba joanacoeli@uol.com.br

\section{Title}

Who tell tale, raises a point, who review, raise several.

\section{Título}

Quien cuenta um cuento, aumenta um puento, quien reseña, aumenta vários. 